\title{
INCIDENCE OF FLUID INCLUSIONS ON THE CHEMICAL QUALITY OF SALT PRODUCED IN SFAX SALINE (E.S OF TUNISIA)
}

\section{R. AMDOUNI}

Received: 26/06/06

Accepted: 24/09/08

\author{
Laboratory of analysis, General Company of Tunisian saline \\ CO.TU.SAL-Gabes Road Km 0.5, \\ P.O Box 86-3018 Sfax-Tunisia
}

*to whom all correspondence should be addressed: e-mail: ridam@cotusal.com.tn

\begin{abstract}
Halite-crystals produced in solar salts Works of Sfax Saline (E.S of TUNISIA), more often, contain fluid inclusions which fill inter- and intra-crystalline cavities and represent from 3 to $5 \%$ in mass.

With the sole aim of quantifying the impact of fluid inclusions on chemical quality of $\mathrm{NaCl}$ crystals, we proceeded by a comparison of the analytical results obtained from the analysis of primary salt samples with those obtained upon the same samples cleared out as much as possible of their inclusions by grinding in ethanol. The results obtained for bromine, potassium, magnesium and heavy metals ( $\mathrm{Cu}, \mathrm{Mn}, \mathrm{Pb}, \mathrm{Zn}$ and $\mathrm{Cd}$ ) show that these inclusions have a chemical composition similar to that of mother brines. The decrease of salt -crystals size, by washing, using saturated brines, largely contributes to the reduction of impurities in alimentary sea salt.
\end{abstract}

KEYWORDS: brines, cavities, salinity, solar salts works, fluid inclusions, heavy metals.

\section{INTRODUCTION}

Salt crystals that precipitate in Sfax saline crystallizers (see Figure 1) contain some impurities. We can mention inorganic compounds that are either chemical element dissolved in fluid inclusions or substituting sodium and chlorine in $\mathrm{NaCl}$ crystal lattice; or fine solid particles that are inter- or intracrystalline. Fluid inclusions, whose abundance is a function of growth rate of crystal, contain the same concentrations in chemical elements similar to their mother brine. Thus, this constitutes a major source of halite pollution.

In this paper, we report the quality and state of impurities and their effect on the chemical quality of alimentary sea salt. In addition, we present a discussion of the relationship between inclusions process and the crystallising conditions (physical-chemical proprieties of the generating brines and kinetic crystalline growth).

\section{SAMPLING AND EXPERIMENTAL METHODS Sampling}

Nine samples of salt were taken in crystallizers and four others in different stages of washing. Besides, to compare the chemical composition of inclusions fluid and that of the mother brine, nine samples of this last were taken in the same ponds than those of salts.

\section{Preparations and analyses}

Solutions: After filtration and acidification, the brines were analysed by spectrometry of atomic absorption with flame (GBC 902, for major elements) and with furnace (HITACHI Z-7000, for heavy metals). Bromine was analysed by volumetric method. All analytical methods were adapted to this media of high salinity (Amdouni, 1990).

Salts: To characterise brines of inclusions, we proceeded by a comparison of values obtained on the primary salt samples with those obtained on the same samples ridded to the maximum of their inclusions by grinding in the ethanol. After drying, its dissolution has been achieved with the demineralised water. The analyses of the majors and the traces elements have been realised upon filtered solutions and according to the same procedure with the brines. 


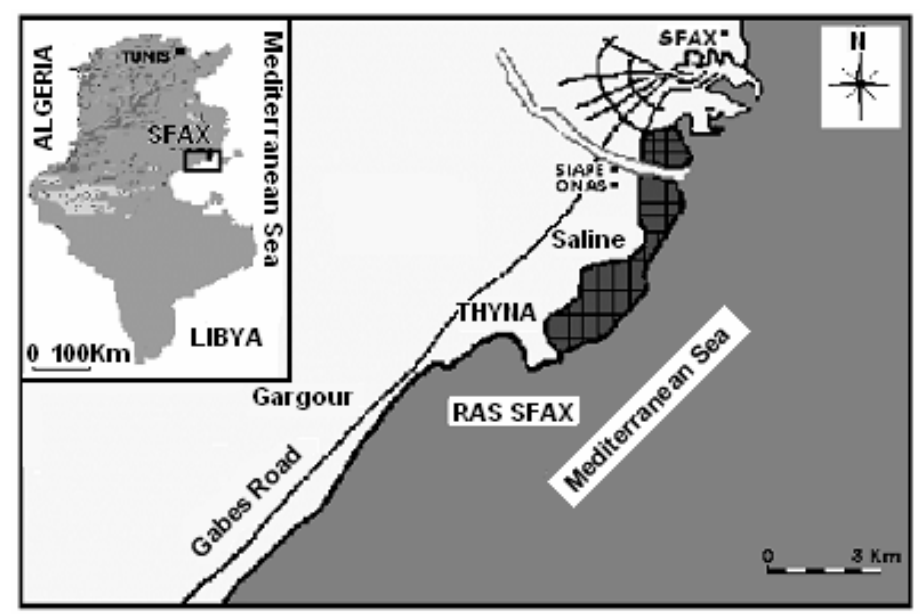

Figure 1. Location map of Sfax saline (S.E Tunisia)

\section{RESULTS AND DISCUSSIONS}

\section{Growth way of halite crystals precipitating in crystallizers of Sfax saline}

The different observation carried out on samples of salts coming from crystallizers permitted us to identify two varieties of halite: milky halite and limpid halite. The distinction between these two aspects is essentially founded on the presence or the absence of fluid inclusion:

a. The milky halite is characterised by its troubled aspect and its whitish colour, resulting from the abundance of fluid inclusion.

b. The limpid halite is characterised by its limpid aspect resulting from the rarity of fluid inclusions.

Three types of structures could have been identified: hoppers shape, chevrons shape and the inverse pyramids shape (see Figure 2 and Figure 3):

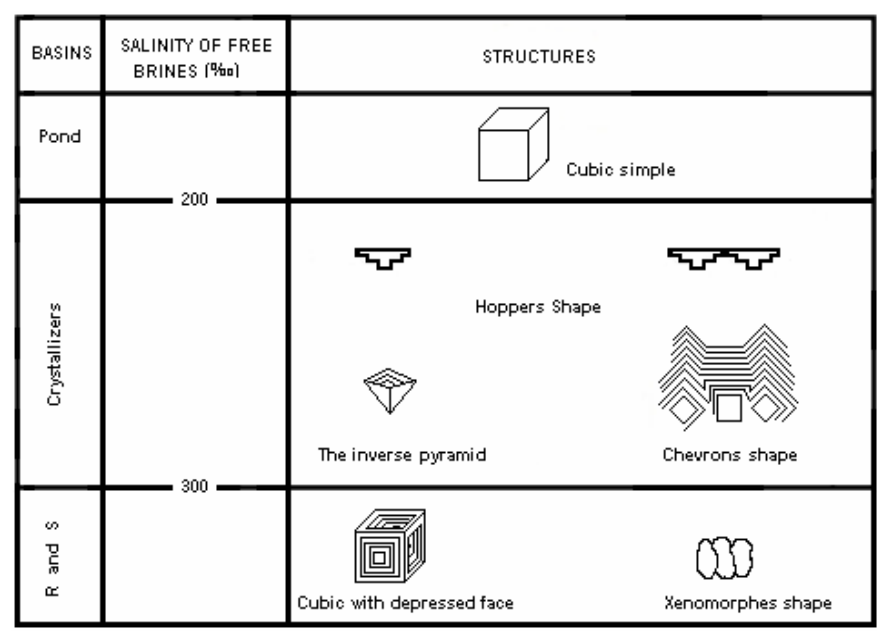

Figure 2. Different shapes of halite crystals precipitating in crystallizers of Sfax saline
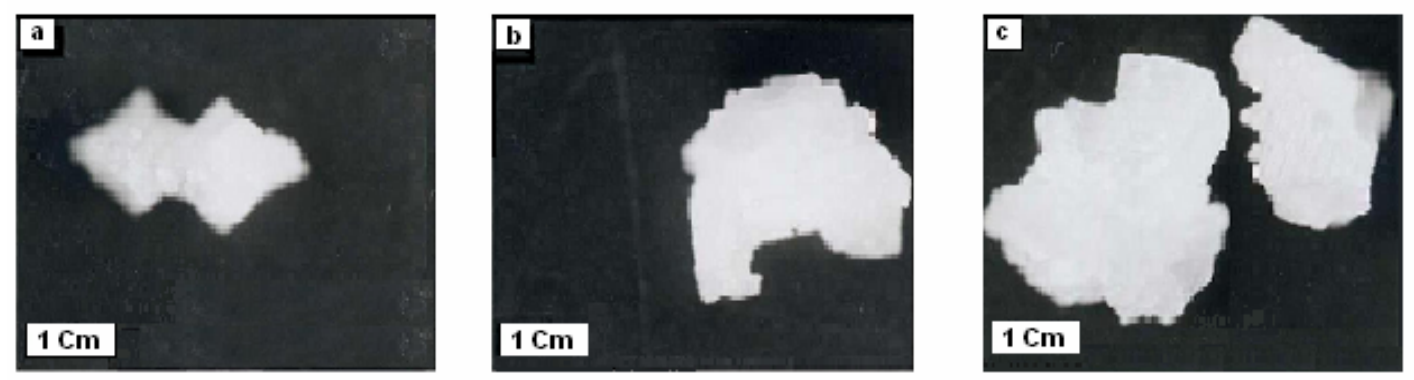

Figure 3. Different shapes of halite crystal observed in crystallizers of Sfax saline a: Hoppers shape b: Inverse pyramids shape c: Chevrons shape 


\section{Physical states of impurities}

As we have already indicated it in a previous publication (Amdouni et al., 1990), the contained impurities in the halite of Sfax saline are especially inorganic composites. These contaminants are either in the form of chemical elements dissolved in fluid inclusions or replacing the sodium and chlorine in the crystalline network of $\mathrm{NaCl}$; or in the form of fine solid particles inter or intracrystalline (see Figure 4).

The abundance of impurities, their nature and their distribution within the crystalline mass depend closely on the chemical composition of the mother brine, of the quantity of suspended matter and the kinetics of crystal growth. The solid impurities (insoluble matter) are generally represented by the fine sedimentary and organic particles and brought by wind or/and pulled out to the substratum of crystallizers during the harvest of salt. They can also be like the evaporitic mineral precipitating at the same time as the halite (gypsum, sylvia). On the other hand, the fluid inclusions correspond to mother brines trapped in the cavity inter and intra-crystalline. The distribution and the abundance of these cavities, developed during the growth of $\mathrm{NaCl}$ crystals, also depend on the state of solution concentration and the kinetics of crystallisation.

In an agitated environment, crystals of halite contain numerous inclusions and characterise themselves by their little size. When the growth is slow (calm environment) the halite that precipitates is limpid and crystals are of centimetric size.

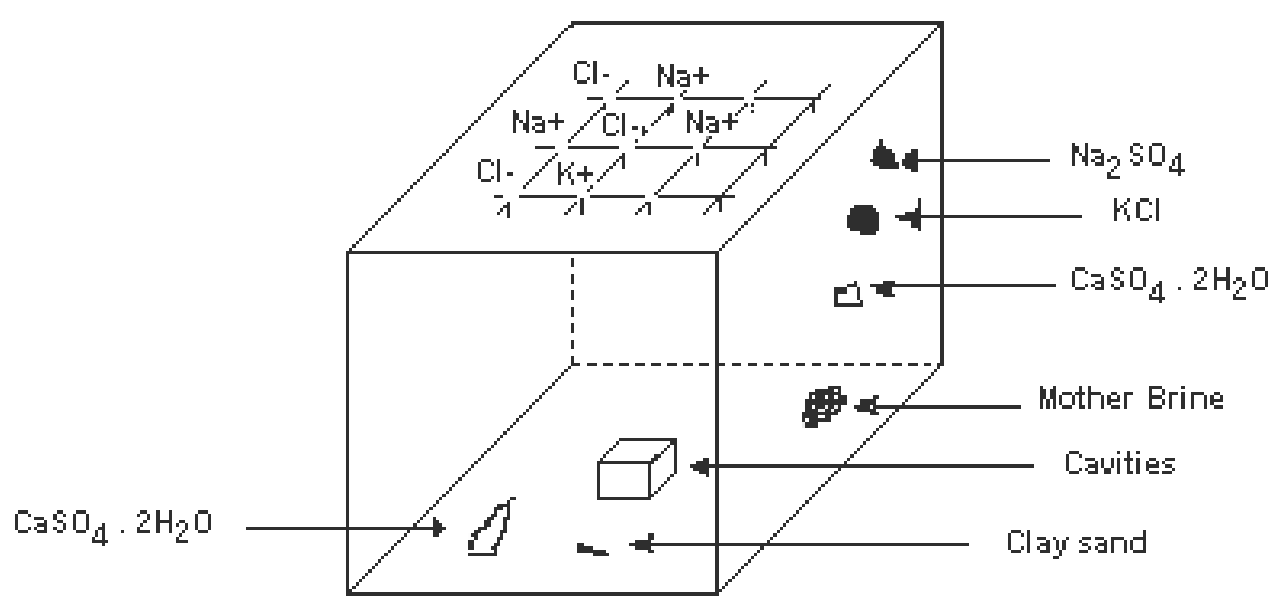

Figure 4. Different types of Impurities that can be met in crystals of halite (according to Mazuzawa, 1978)

\section{Characterisation of brine inclusions}

As we have previously signalled, the liquid inclusions constitute the main part of impurities met in crystals of sodium chlorine. With the aim to quantify the impact of brine inclusions and those of impregnation on the chemical quality of the halite, we proceeded by a comparison of values obtained from the analysis of the primary salt samples and those obtained on the same samples ridded to the maximum of their inclusions by grinding in the ethanol. The results acquired for the potassium; magnesium and bromine are given in the table 1. They show a fall for the three elements and more especially for $\mathrm{Mg}$, whose content can lower $60 \%$. This element cannot enter in the crystalline network of the halite, can only be brought by the fluid inclusions. Therefore, its total elimination permits to control the elimination of inclusions.

While reporting on a diagram, contents in magnesium and bromine, at the same time in the primary salt samples and these same samples ground in the ethanol, one notices a reduction of contents that materialises by straight lines having roughly the same slope (see Figure $5 \mathrm{a}$ ). The diagram traced from values in magnesium and potassium (see Figure 5b) shows also a regression of contents, but following the slopes that are relatively stronger than those obtained in the case of the bromine. 
Table 1. Comparative results (expressed in mole $\mathrm{kg}^{-1}$ ) of contents in $\mathrm{K}, \mathrm{Br}$ and $\mathrm{Mg}$ for nine salt samples taken in crystallizers

$\left(1^{\text {st }}\right.$ line: primary salt sample, $2^{\text {nd }}$ line: sample grinding in the ethanol)

\begin{tabular}{cccc}
\hline \multirow{2}{*}{ Samples } & $\mathbf{K}$ & $\mathbf{B r}$ & $\mathbf{M g}$ \\
& $10^{-3}$ & $10^{-3}$ & $10^{-3}$ \\
\hline \multirow{2}{*}{ RTS2 } & 21.74 & 2.05 & 47.30 \\
\cline { 2 - 4 } & 20.46 & 1.99 & 41.13 \\
\hline \multirow{2}{*}{ RTS9 } & 20.46 & 1.86 & 42.69 \\
\cline { 2 - 4 } & 14.83 & 1.66 & 23.86 \\
\hline \multirow{2}{*}{ RTS11 } & 26.34 & 2.11 & 53.06 \\
\cline { 2 - 4 } & 25.06 & 2.04 & 45.25 \\
\hline \multirow{2}{*}{ RTS20 } & 14.07 & 1.79 & 43.48 \\
\cline { 2 - 4 } & 11.25 & 1.64 & 27.97 \\
\hline \multirow{2}{*}{ RTS27 } & 17.13 & 1.85 & 39.20 \\
\cline { 2 - 4 } & 11.25 & 1.61 & 15.63 \\
\hline \multirow{2}{*}{ RTS32 } & 10.49 & 1.70 & 26.98 \\
\cline { 2 - 4 } & 7.16 & 1.54 & 12.34 \\
\hline \multirow{2}{*}{ RR1 } & 31.71 & 1.85 & 64.08 \\
\cline { 2 - 4 } & 28.64 & 1.70 & 41.13 \\
\hline \multirow{2}{*}{ RS11 } & 38.36 & 2.13 & 82.26 \\
\cline { 2 - 4 } & 34.53 & 1.94 & 50.18 \\
\hline \multirow{2}{*}{ RS51 } & 34.53 & 1.76 & 83.29 \\
\cline { 2 - 4 } & 31.07 & 1.63 & 53.47 \\
\hline
\end{tabular}

As the total elimination of the magnesium permits us to control the one of the fluid inclusions, it is possible, from these diagrams to extrapolate results in order to get the real contents in $\mathrm{Br}$ and $\mathrm{K}$ that co-precipitate with the halite, while bringing back the content in magnesium to zero for samples that have not been ridded completely of this element. In the same way, we corrected the contents of heavy metals ( $\mathrm{Cu}, \mathrm{Mn}, \mathrm{Pb}, \mathrm{Zn}$ and $\mathrm{Cd})$. Results obtained after correction are in the table 2.

Table 2. Contents in mole. $\mathrm{kg}^{-1}$ of $\mathrm{K}, \mathrm{Br}, \mathrm{Cu}, \mathrm{Mn}, \mathrm{Pb}, \mathrm{Zn}$ and $\mathrm{Cd}$ after total elimination of fluid inclusions (nd: undetected)

\begin{tabular}{cccccccc}
\hline Samples & $\begin{array}{c}\mathbf{K} \\
10^{-2}\end{array}$ & $\begin{array}{c}\mathbf{B r} \\
10^{-3}\end{array}$ & $\begin{array}{c}\mathbf{C u} \\
10^{-6}\end{array}$ & $\begin{array}{c}\mathbf{M n} \\
10^{-6}\end{array}$ & $\begin{array}{c}\mathbf{P b} \\
10^{-6}\end{array}$ & $\begin{array}{c}\mathbf{Z n} \\
10^{-6}\end{array}$ & $\begin{array}{c}\mathbf{C d} \\
10^{-6}\end{array}$ \\
\hline RTS2 & 1.193 & 1.573 & 2.34 & 27.30 & nd & 22.33 & 0.09 \\
\hline RTS9 & 0.771 & 1.397 & 2.24 & 20.59 & nd & 20.50 & 0.19 \\
\hline RTS11 & 1.766 & 1.621 & 0.87 & 26.19 & nd & 20.19 & 0.07 \\
\hline RTS20 & 0.618 & 1.382 & 0.74 & 22.30 & nd & 23.25 & 0.10 \\
\hline RTS27 & 0.735 & 1.461 & 1.04 & 29.47 & nd & 18.66 & 0.08 \\
\hline RTS32 & 0.436 & 1.402 & 1.49 & 16.05 & nd & 9.48 & 0.19 \\
\hline RR1 & 2.314 & 1.433 & 0.59 & 31.23 & nd & 40.39 & 0.14 \\
\hline RS11 & 2.852 & 1.646 & 11.84 & 29.32 & 1.04 & 0.61 & 0.90 \\
\hline RS51 & 2.488 & 1.383 & 4.03 & 57.05 & 1.16 & 3.82 & 0.71 \\
\hline
\end{tabular}



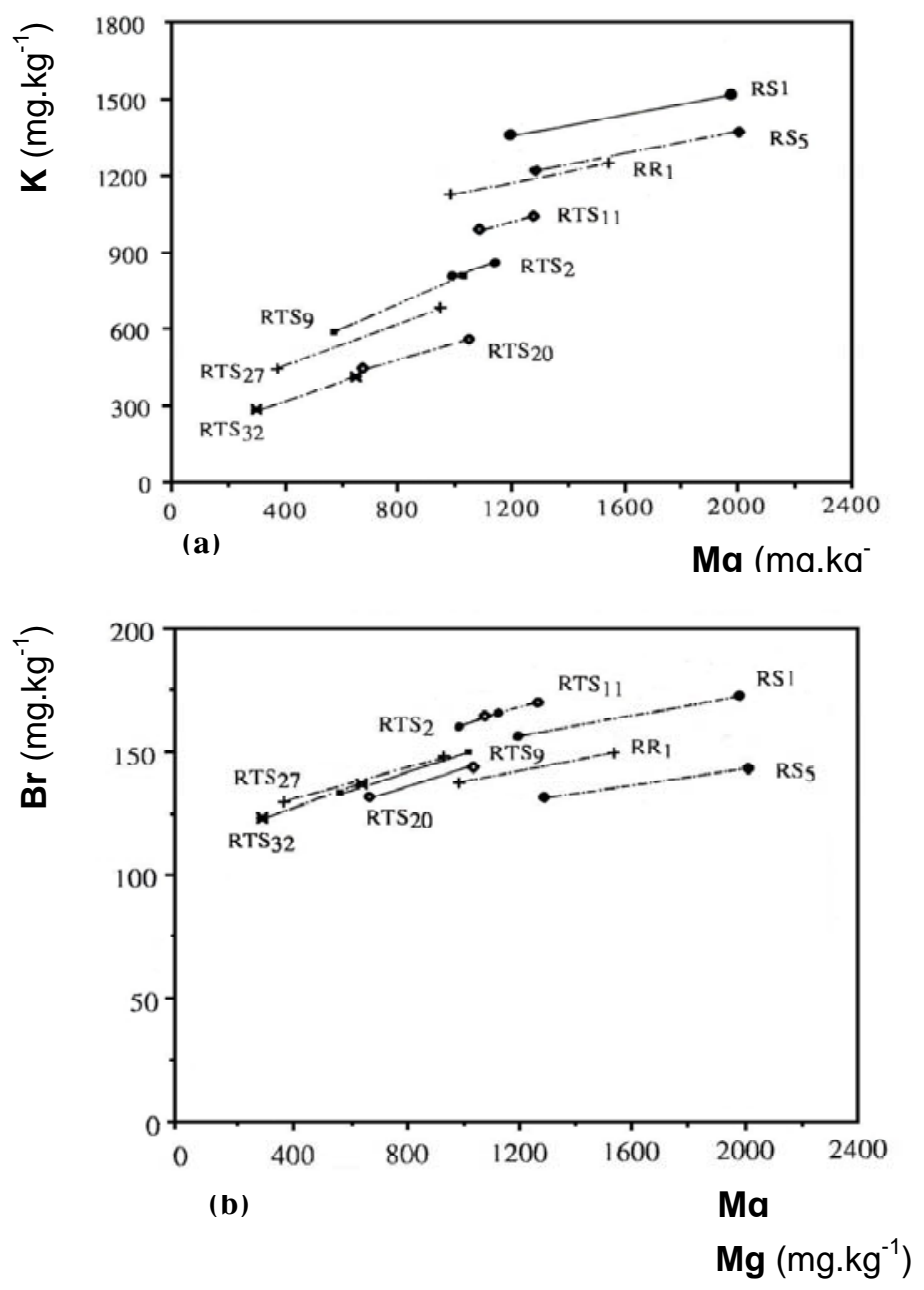

Figure 5. Diagrams showing the reduction of contents in $\mathrm{Br}, \mathrm{K}$ and $\mathrm{Mg}$ in halite crystals after their grinding in the ethanol

From diagrams (Figures $5 \mathrm{a}$ and $5 \mathrm{~b}$ ), used for the correction of the quantity of $\mathrm{Br}$ and $\mathrm{K}$ in halite crystals by report to fluid inclusions, one observes a linear reduction of concentrations of these two elements following the slopes noticeably the same for the different samples. This proportionality shows that brines trapped in cavity intra-crystalline possess roughly the same composition because they're relative variation is identical in all samples.

We tried to characterise fluid inclusions and their relations with the free brines. For it, we proceeded to an assessment of the concentration in $\mathrm{Br}, \mathrm{K}$ and $\mathrm{Mg}$ in fluid inclusions, from results extrapolated and those obtained on the primary samples (table 3)

Table 3. Contents (expressed in mole. $\mathrm{kg}^{-1}$ ), of the $\mathrm{Br}, \mathrm{K}$ and $\mathrm{Mg}$ in brine inclusions

\begin{tabular}{cccc}
\hline Samples & $\begin{array}{c}\mathbf{M g} \\
10^{-3}\end{array}$ & $\begin{array}{c}\mathbf{K} \\
10^{-3}\end{array}$ & $\begin{array}{c}\mathbf{B r} \\
10^{-3}\end{array}$ \\
\hline RTS2 & 47.30 & 9.80 & 0.47 \\
\hline RTS9 & 42.69 & 12.75 & 0.46 \\
\hline RTS11 & 53.06 & 8.68 & 0.49 \\
\hline RTS20 & 43.47 & 7.88 & 0.40 \\
\hline RTS27 & 39.19 & 9.78 & 0.38 \\
\hline RTS32 & 26.98 & 6.12 & 0.30 \\
\hline RR1 & 64.08 & 8.56 & 0.41 \\
\hline RS11 & 82.26 & 9.83 & 0.48 \\
\hline RS51 & 83.29 & 9.64 & 0.38 \\
\hline
\end{tabular}


The result shows that the part of each of the three elements is approximately the same in all samples, with the middle values of $0.8 \%, 15.5 \%$ and $83.7 \%$ respectively for $\mathrm{Br}, \mathrm{K}$ and $\mathrm{Mg}$. The comparison of these contents with those measured in mothers brines show that the obtained values are nearly identical (see Figure 6). The light difference could be owed to the analytic mistakes.

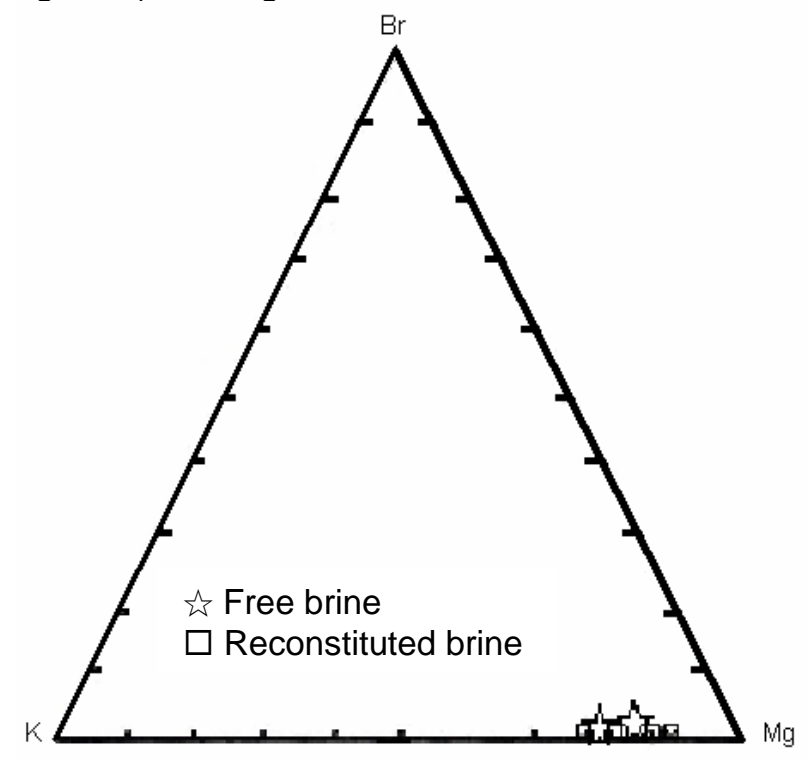

Figure 6. Composition of fluid inclusions compared to the one of the mother brines of halite crystals

It is also possible, thanks to data obtained from the assessment of the quantity of the bromine in fluid inclusions and to the value of the $b$ "coefficient ", to appraise the volume occupied by the fluid inclusions. If one considers $\mathrm{Br}_{i}$ and $\mathrm{Br}_{\mathrm{f}}$, respectively the content $\left(\mathrm{mg} \mathrm{kg}^{-1}\right)$ of the bromine in the primary halite (halite with its inclusions) and the one obtained after total elimination of inclusions (extrapolated bromine concentration); the percentage in mass, noted " $\mathrm{M}$ ", of the fluid inclusions can be determined while using the following formula (Moretto, 1988):

$$
M(\%)=\frac{\left(\mathrm{Br}_{i}-\mathrm{Br}_{\mathrm{f}}\right)}{\frac{\mathrm{Br}_{\mathrm{f}}}{\mathrm{b}}+\left(\mathrm{Br}_{\mathrm{i}}-\mathrm{Br}_{\mathrm{f}}\right)} \times 100
$$

$\mathrm{b}$ : distribution coefficient of bromine between free brine and halite crystals

$$
\mathrm{b}=\frac{\mathrm{Br}(\%) \text { in halite crystal }}{\mathrm{Br}(\%) \text { in free brine }}
$$

The value of " $b$ " is equal to 0.13 (Braitsch and Herrmann, 1963). The obtained results are given in the Table 4.

Once the fluid inclusion percentage is determined, we can reconstitute the chemical composition of the mother brines. The obtained results, compared with those obtained for the free brines, are given in the Table 4.

Impact of the insoluble particles and the fluid inclusions on the chemical quality of the alimentary sea salt

The halite crystals deposited in the crystallizers of Sfax saline contain 0.07 to $0.16 \%$ of insoluble matter, 0.18 to $0.28 \%$ of calcium ions, 0.06 to $0.11 \%$ of ions potassium, 0.20 to $0.35 \%$ of ions magnesium, 0.19 to $0.32 \%$ of ions sulphates and 0.0005 to $0.001 \%$ of heavy metals. The quantity of impurities closely varies with the size of crystals and the chemical quality of mother brines. After washing with saturated water, the quantity of impurities is very reduced (total impurities $<0.03 \%$ ). In the halite of consumption, it is lower than $0.01 \%$.

With regard to the physical state of impurities and their origins, the ion of calcium and sulphates are brought in part by gypsum. The potassium, the bromine and most of the heavy metals $(\mathrm{Cu}, \mathrm{Mn}, \mathrm{Pb}, \mathrm{Zn}$ and $\mathrm{Cd}$ ) are present as well in the crystalline network (substitution of the sodium and chlorine) that in brines of inclusions. These solutions also contain $\mathrm{Mg}, \mathrm{Ca}$ and $\mathrm{SO}_{4}$. 
Table 4. Evaluation of the percentage of fluid inclusions and the composition of the mother brine, compared to those obtained from the free brine analysis Contents are expressed in mole $\mathrm{kg}^{-1}$. (1):

Reconstituted brine (2): Mother brine

\begin{tabular}{ccccccccc}
\hline Samples & $\begin{array}{c}\text { Salinity } \\
\text { of free } \\
\text { brines }\end{array}$ & $\mathbf{M}$ & \multicolumn{2}{c}{$\mathbf{M g}$} & \multicolumn{2}{c}{$\mathbf{K}$} & \multicolumn{2}{c}{$\mathbf{B r}\left(10^{-3}\right)$} \\
\hline RTS2 & 283.12 & 3.81 & 1.241 & 1.154 & 0.257 & 0.229 & 12.580 & 12.550 \\
\hline RTS9 & 281.43 & 4.17 & 1.023 & 1.085 & 0.305 & 0.205 & 11.211 & 11.610 \\
\hline RTS11 & 296.43 & 3.81 & 1.391 & 1.338 & 0.228 & 0.261 & 12.960 & 12.140 \\
\hline RTS20 & 293.60 & 3.70 & 1.176 & 1.338 & 0.213 & 0.272 & 11.035 & 11.950 \\
\hline RTS27 & 287.50 & 3.31 & 1.183 & 1.265 & 0.295 & 0.243 & 11.622 & 12.240 \\
\hline RTS32 & 285.94 & 2.71 & 0.996 & 0.765 & 0.226 & 0.147 & 11.082 & 9.310 \\
\hline RR1 & 295.32 & 3.66 & 1.749 & 1.494 & 0.234 & 0.280 & 11.441 & 11.037 \\
\hline RS11 & 321.70 & 3.66 & 2.247 & 3.234 & 0.269 & 0.585 & 13.144 & 14.790 \\
\hline RS51 & 318.27 & 3.46 & 2.405 & 2.773 & 0.278 & 0.782 & 11.019 & 13.780 \\
\hline
\end{tabular}

The exam of figure 7 , that represents the quantitative sequence of crystallisation of the different elements studied as a function of a concentration factor (Amdouni, 1990), show that the halite is a susceptible mineral to stock most of heavy metals in addition to $\mathrm{K}$ and $\mathrm{Br}$. Nevertheless, contents remain very limited and do not constitute any danger for human life. Another source of pollution, of which one must hold in account, is the wind contribution. Indeed a good part of solid impurities correspond to the other minerals that gypsum. This type of pollution appears by the relatively elevated contents in calcium, silica and aluminium. In the halite, destined to the human consumption, impurities (solid and liquid) are very reduced and even inexistent because of the reduction of the crystal size by washing. Therefore, the nourishing salt produced in Sfax saline is of good quality

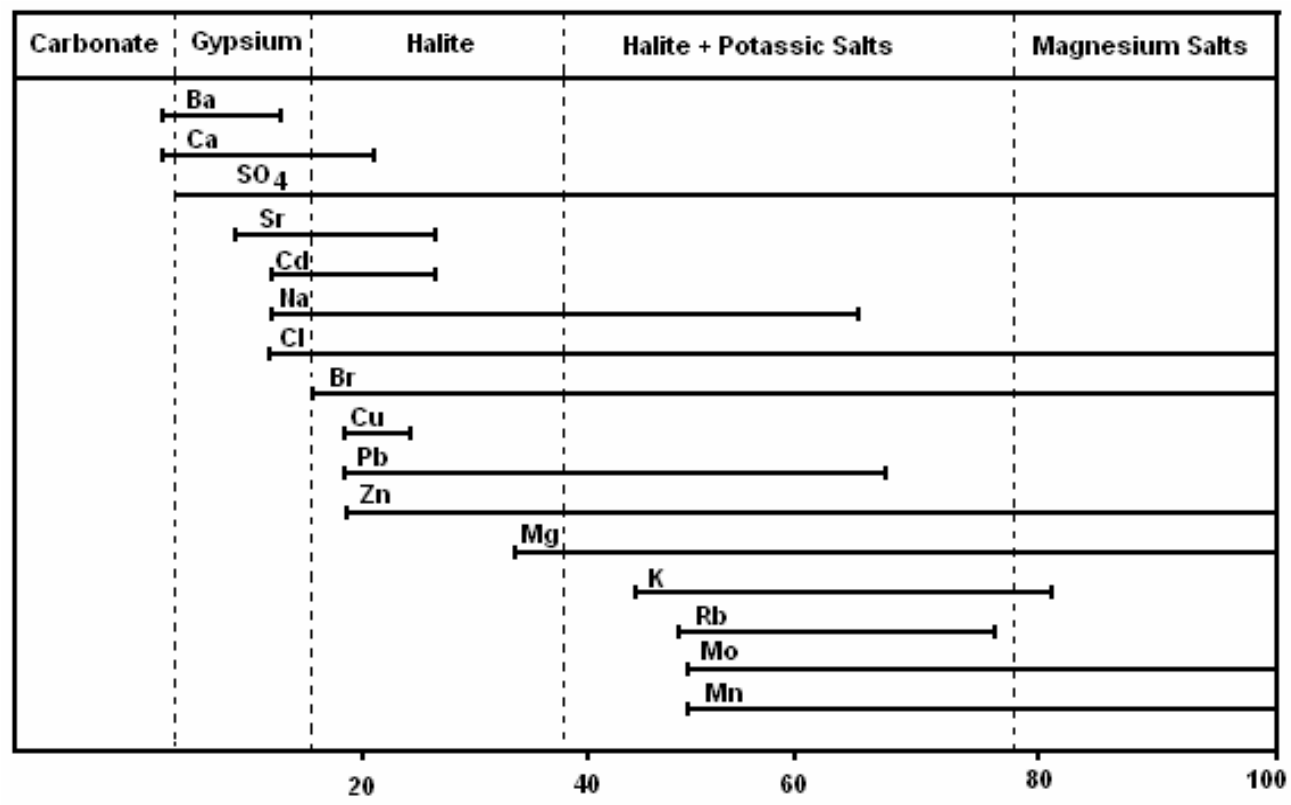

Figure 7. Sequence of crystallisation of some chemical elements during the evaporation Of seawater (according to Amdouni, 1990)

\section{CONCLUSIONS}

According to this survey, we can conclude that the abundance of fluids or solids inclusions is a function of growth rate of the halite crystals. Indeed, the deposit conditions play a decisive role in the kinetics of crystallization and, thus, control the degree of purity of the sodium chloride. The fluids 
inclusions, which contain the same chemical composition as the mother brine, constitute a major source of halite pollution. To minimize the fluid inclusions, it is necessary to be careful that the environment of precipitation is not very agitated. Therefore, it is necessary to ensure that the bottom of the crystallizer is properly leveled and that the thickness of the free brine is well controlled during the production period. An average level of brine, ranging from 40 to $50 \mathrm{Cm}$ is sufficient to minimize the agitation of water in ponds and therefore the salt that precipitates will be poor in fluid inclusion. On the contrary, a low thickness of the slice of brine (less than10 $\mathrm{cm}$ ) associated with high evaporation leads to the precipitation of small salt crystals rich in fluid inclusions. Similarly, it must be ensured that the feeding of crystallizers must be carried out at low speed and with saturated brine. Indeed, the addition of a large volume of under saturated water causes dilution of the existing brines. These dilutions have as effect, the brutal cessation of the crystallization and a possible dissolution of the salt layer previously deposited. This same phenomenon is also obtained as a result of the falling of a significant amount of rain. In this case the drains gates must be adjusted to facilitate the rapid evacuation of freshwaters, which can lead to the dilution of saturated brine.

The solid impurities are generally present in the form of little gypsum crystals that precipitate in the same time as the halite or in form of fine sedimentary (clay, sand, ..) and organic particles carried by wind or/and pulled out to the substratum of crystallizers during the harvest of salt. To reduce the quantities of insoluble matters in the product, it is advisable to cover the dikes and roads between the basins by fine salt. These impurities can be also largely reduced during the washing of salt.

Finally, we can conclude that although the major elements and metals traces have the possibility to be stocked in crystals of salt, their contents remain very low in relation to the tolerable limits fixed by the FAO for the salt destined to the human consumption.

\section{REFERENCES}

Amdouni R., (1990), Etude géochimique des saumures libres, des sédiments et des sels dans la saline de Sfax (Tunisie), Thèse de l'Université Paris IV, Paris.

Amdouni R., Boulègue J. and Médhioub K., (1990), Influence de la pollution de l'eau de mer sur la qualité chimique de l'halite dans les cristallisoirs de la saline de Sfax (Tunisie), $2^{\text {ème }}$ congrès National des sciences de la Terre. Tunis 1990.

Braitsch O. and Herrmann A.G., (1963), Zur Geochemie des broms in salinaren sedimen. Teil I: Experimentelle bestimmung der $\mathrm{Br}$ Verteilung in verschiedenen natürlichen Salzsystemen. Geochimi. Cosmoch. Acta, 27, 361-391.

Mazuzawa T., (1978), Impurities contained inside the crystals of solar and vacuum evaporated salts. Symposium on salt. Northern. Ohio, Geol. Ser. Claveland, Ohio.

Moretto R., (1988), Observations on the incorporation of trace elements in halite of Oligocene salt beds, Bourg-en-Bresse Basin, France. Geochimi. Cosmoch. Acta, 52, 2809-2814. 